\title{
Biotinidase, as a Convenient Diagnostic and Prognostic Marker for Breast Cancer
}

\author{
Nader Saki ${ }^{1}$; Soheila Nikakhlagh ${ }^{1}$; Gholamabbas Dinarvand ${ }^{1, *}$ \\ ${ }^{1}$ Cancer Research Center, Jundishapur University of Medical Sciences, Ahvaz, IR Iran \\ *Corresponding author: Gholamabbas Dinarvand, Cancer Research Center, Jundishapur University of Medical Sciences, Ahvaz, IR Iran. Tel: +98-9358521989, E-mail: ab55di@gmail. \\ com
}

Received: January 21, 2015; Accepted: February 2, 2015

\begin{abstract}
According to the definition by the National Institutes of Health of USA, a biological marker (biomarker) is a characteristic that is objectively measured and evaluated, as an indicator of normal biological processes, pathogenic processes or pharmacological responses, to a therapeutic agent. Several studies have reported that a decreased regulating gene expression of biotinidase(BTD) is associated with breast cancer. On the basis of these evidences, we hypothesize that in the serum of breast cancer patients, with different pathological grades, reductions in serum BTD enzyme activities, there are significant differences. The use of this marker, as a diagnostic and prognostic marker for breast cancer, is a promising perspective for the clinical field.
\end{abstract}

Keywords: Biotinidase; Biomarkers; Breast Neoplasms

\section{Background}

\subsection{Tumor Marker}

More than $30 \%$ of people will develop some form of cancer during their lifetime. It is estimated that almost 1.5 million new cases will be diagnosed in USA in 2009 and approximately 600000 of them are expected to die from cancer (1). Four out of 200 forms of cancer (lung, prostate, colon and breast) account for about half of all deaths among cancer patients, men or women (1). Detection of cancer, when it is still localized, and administration of early treatment usually lead to better clinical outcomes (2). One goal of medical screening is to detect human malignancy via a simple blood test. According to the definition by the National Institutes of Health of USA, a biological marker (biomarker) is a characteristic that is objectively measured and evaluated, as an indicator of normal biological processes, pathogenic processes or pharmacological responses to a therapeutic agent. Research during the last 50 years resulted in the identification of clinically useful cancer biomarkers, such as carcinoembryonic antigen (CEA), alpha-fetoprotein (AFP), prostate-specific antigen (PSA), cancer antigen 125 (CA 125), CA 15-3 and CA 19-9. However, most of these biomarkers lack the necessary specificity and sensitivity for screening purposes (3). Currently, there is a need for discovery of diagnostic methods, with improved performance. Over the past decade, with the completion of the Human Genome Project and the introduction of technologies that enable simultaneous examination of thousands of proteins and genes (such as mass spectrometry and protein and DNA arrays), renewed interest, of the proteomics and genomics community, emerged to advance the discovery of novel cancer biomarkers. Extensive proteomic analysis of a variety of different sample types has been conducted to dig deeper into the cancer cell proteome and reveal promising biomarkers. As mentioned earlier, blood is considered the sample of choice for medical screening or diagnosis. The advantages of such simple and relatively noninvasive blood-based tests are obvious. However, biomarker discovery using plasma or serum is challenging $(4,5)$. Given the limitations of blood-based biomarker discovery, alternative approaches have been pursued, including proteomic analysis of proximal body fluids, cancer tissues and cancer cell lines, to reveal tumor markers in these samples. Breast cancer is one of the most common cancers in women, worldwide (6). Although early detection and treatment of breast cancer in patients showed good prognosis, current diagnostic techniques, such as mammography, magnetic resonance imaging (MRI) and positron emission tomography (PET) are not sufficient to detect early stages of breast cancer, efficiently (7). Finding a series of relevant biological markers for early cancer detection and diagnosis, and monitoring the therapeutic response can definitely improve our ability to manage breast cancer (810). An emerging issue of proteomics is to discover novel biological markers that can be applied to early detection, disease diagnosis and prediction of response to therapy (11). Proteomics has advanced direct profiling of differentially expressed proteins between diseased and control 
samples, or at various stages of diseases, under particular environments (12), and therefore has become a key technology in the biomarker development pipeline. The biomarker pipeline can be divided into four phases: discovery, qualification, verification and validation phases (13). The discovery phase is an unbiased and semi-quantitative process, usually comprising simple binary comparisons between diseased and normal state. Tissues, body fluids, or even model cell lines are being utilized as proteome sources. The "products" of the discovery phase are confirmed in the next qualification phase. Immunoassays with commercially available antibodies can be used. In the verification phase, the analysis is extended to a larger number of samples, now incorporating a broader range of cases and controls. Although any proteome source can be used in the discovery phase, biomarkers that are detected and validated in specimens obtained by less invasive techniques, such as plasma or serum, are more desirable $(13,14)$. The blood serum or plasma contains an enormous complexity of biological components, which reflect spatiotemporal changes of diseased cells, tissues, or organs (15). Knowledge of any change in the containment of blood, caused by a specific disease, like cancer, will help us understand and develop detection and further management of the disease. The objective of our study is to discover new breast cancer biomarkers, using blood plasma, as proteome sources. We previously analyzed breast cancer tissues (16) and secretome from a breast cancer cell line (17).

\subsection{Biotinidase}

Biotinidase (BTD) enzyme (EC 3.5.1.12) is an important enzyme in the metabolism of biotin, which is the valuable degradation product resulting from the catalysis of the biocytin ( $\varepsilon$-N-biotinyl lysine) carboxylase, catalyzing $(18,19)$. The activity of BTD takes place in the liver, kidney, intestine and serum (20). Recently, a novel posttranslational modification of histones has been identified: biotinylation of lysine residues (21). The covalent binding of biotin to histones is mediated by BTD and holocarboxylase synthetase (HCS) $(22,23)$. Biotinidase uses biocytin (biotinyl- $\varepsilon$ - lysine), as a substrate for biotinylation of histones (22), whereas HCS uses biotin and ATP (23). The following biotinylation sites have been identified in human histones: K4, K9, and K18, in histone $\mathrm{H} 3$ (24), and $\mathrm{K} 8$ and $\mathrm{K} 12$, in histone $\mathrm{H} 4$ (25). Biotinylation of histones plays a role in the regulation of gene expression, cell proliferation (21,22), and the cellular response to DNA damage (26, 27). A study of Kang et al. in 2010, reported that decreased regulating gene expression of BTD is strongly associated with breast cancer (28).

\section{Hypothesis}

As mentioned above, the biotinilation of histones based on BTD action can regulate gene expression. On the other hand, Kang et al. revealed by techniques of proteomics re- search that the BTD gene expression is reduced in breast cancer (28). The enzyme activity in serum of breast cancer patients is low, Also, the same study concluded that BTD serum levels, in grades 1, 2, 3 and 4 breast cancer, are reduced, except the zero grade (28). Therefore, it can be hypothesized that BTD reductions in grades 1, 2, 3 and 4 is also different, making BTD determination in the serum a non-invasive marker, that can be correlated with pathological changes in a tissue sample. Consequently, a BTD tumor diagnosis can be obtained with just a simple blood sampling and measurement of these serum enzyme activities in patients with breast cancer. Also, the effects of different treatment protocols can be assessed, by determining the enzymatic activity, in the evaluation of tumor prognosis. In order to accept or reject this theory, its impact on patient acceptance, as a non-invasive cancer staging and monitoring technique, should be taken into consideration. Also, this idea should be perpetuated for its important role and implications for future use.

\section{Consequences of the Hypothesis and Conclusion}

In summary, according to the theory mentioned above, we would use the awareness of the changes in serum enzyme activities in patients compared to healthy subjects BTD grads, and between different tumors and different enzyme levels, in patients. This enzyme can effortlessly be used, as a convenient tumoral biomarker, for the diagnosis and prognosis of breast cancer.

\section{Acknowledgements}

This hypothesis is based on our present study in the Cancer Research Center, Ahvaz Jundishapur University of Medical Sciences, Ahvaz, Iran.

\section{Funding/Support}

Funding for this study was provided by the Cancer Research Center, Ahvaz Jundishapur University of Medical Sciences, Ahvaz, Iran.

\section{References}

1. Jemal A, Siegel R, Ward E, Hao Y, Xu J, Thun MJ. Cancer statistics, 2009. CA Cancer JClin. 2009;59(4):225-49.

2. Etzioni R, Urban N, Ramsey S, McIntosh M, Schwartz S, Reid B, et al. The case for early detection. Nat Rev Cancer. 2003;3(4):243-52.

3. Khatcheressian JL, Wolff AC, Smith TJ, Grunfeld E, Muss HB, Vogel VG, et al. American Society of Clinical Oncology 2006 update of the breast cancer follow-up and management guidelines in the adjuvant setting. JClin Oncol. 2006;24(31):5091-7.

4. Anderson NL, Anderson NG. The human plasma proteome: history, character, and diagnostic prospects. Mol Cell Proteomics. 2002;1(11):845-67.

5. Omenn GS, States DJ, Adamski M, Blackwell TW, Menon R, Hermjakob H, et al. Overview of the HUPO Plasma Proteome Project: results from the pilot phase with 35 collaborating laboratories and multiple analytical groups, generating a core dataset of 3020 proteins and a publicly-available database. Proteomics. 2005;5(13):3226-45.

6. Veronesi U, Boyle P, Goldhirsch A, Orecchia R, Viale G. Breast can- 
cer. Lancet. 2005;365(9472):1727-41.

7. Tuli R, Flynn RA, Brill KL, Sabol JL, Usuki KY, Rosenberg AL. Diagnosis, treatment, and management of breast cancer in previously augmented women. Breast J. 2006;12(4):343-8.

8. Aebersold R, Anderson L, Caprioli R, Druker B, Hartwell L, Smith R. Perspective: a program to improve protein biomarker discovery for cancer. J Proteome Res. 2005;4(4):1104-9.

9. Hartwell L, Mankoff D, Paulovich A, Ramsey S, Swisher E. Cance biomarkers: a systems approach. NatBiotechnol. 2006;24(8):905-8.

10. Iwaki H, Kageyama S, Isono T, Wakabayashi Y, Okada Y, Yoshimura $\mathrm{K}$, et al. Diagnostic potential in bladder cancer of a panel of tumor markers (calreticulin, gamma -synuclein, and catechol-omethyltransferase) identified by proteomic analysis. Cancer Sci. 2004;95(12):955-61.

11. Somiari RI, Somiari S, Russell S, Shriver CD. Proteomics of breast carcinoma. J Chromatogr B Analyt Technol Biomed Life Sci. 2005;815(1-2):215-25.

12. Lo WY, Tsai MH, Tsai Y, Hua CH, Tsai FJ, Huang SY, et al. Identification of over-expressed proteins in oral squamous cell carcinoma (OSCC) patients by clinical proteomic analysis. Clin Chim Acta. 2007;376(1-2):101-7.

13. Rifai N, Gillette MA, Carr SA. Protein biomarker discovery and validation: the long and uncertain path to clinical utility. Nat Biotechnol. 2006;24(8):971-83.

14. Hu S, Loo JA, Wong DT. Human body fluid proteome analysis. Proteomics. 2006;6(23):6326-53.

15. Siriwardana G, Bradford A, Coy D, Zeitler P. Autocrine/paracrine regulation of breast cancer cell proliferation by growth hormone releasing hormone via Ras, Raf, and mitogen-activated protein kinase. Mol Endocrinol. 2006;20(9):2010-9.

16. Kim DH, Bae J, Lee JW, Kim SY, Kim YH, Bae JY, et al. Proteomic analysis of breast cancer tissue reveals upregulation of actinremodeling proteins and its relevance to cancer invasiveness. Proteomics Clin Appl. 2009;3(1):30-40.

17. Chang JW, Kang UB, Kim DH, Yi JK, Lee JW, Noh DY, et al. Identification of circulating endorepellin LG3 fragment: Potential use as a serological biomarker for breast cancer. Proteomics Clin Appl. 2008;2(1):23-32.

18. Thoma RW, Peterson WH. The enzymatic degradation of soluble bound biotin. J Biol Chem. 1954;210(2):569-79.

19. Wright LD, Driscoll CA, Boger WP. Biocytinase, an enzyme concerned with hydrolytic cleavage of biocytin. Proc Soc Exp Biol Med. 1954;86(2):335-7.

20. Pispa J. Animal biotinidase. Ann Med Exp Biol Fenn. 1965;43:Suppl 5:1-39.

21. Stanley JS, Griffin JB, Zempleni J. Biotinylation of histones in human cells. Effects of cell proliferation. Eur J Biochem. 2001;268(20):5424-9.

22. Hymes J, Fleischhauer K, Wolf B. Biotinylation of histones by human serum biotinidase: assessment of biotinyl-transferase activity in sera from normal individuals and children with biotinidase deficiency. Biochem Mol Med. 1995;56(1):76-83.

23. Narang MA, Dumas R, Ayer LM, Gravel RA. Reduced histone biotinylation in multiple carboxylase deficiency patients: a nuclear role for holocarboxylase synthetase. Hum Mol Genet. 2004;13(1):15-23.

24. Sarath G, Kobza K, Rueckert B, Camporeale G, Zempleni J, Haas E. Biotinylation of human histone $\mathrm{H} 3$ and interactions with biotinidase. FASEB J. 2004;18(4):A103.

25. Wolf B, Grier RE, Allen RJ, Goodman SI, Kien CL. Biotinidase deficiency: the enzymatic defect in late-onset multiple carboxylase deficiency. Clinica Chimica Acta.1983;131(3):273-81.

26. Peters DM, Griffin JB, Stanley JS, Beck MM, Zempleni J. Exposure to UV light causes increased biotinylation of histones in Jurkat cells. Am J Physiol Cell Physiol. 2002;283(3):C878-84.

27. Kothapalli N, Zempleni J. Double strand breaks of DNA decrease biotinylation of lysine-12 in histone $\mathrm{H} 4$ in JAr cells. FASEB J. 2004;18(4):A103-4.

28. Kang UB, Ahn Y, Lee JW, Kim YH, Kim J, Yu MH, et al. Differential profiling of breast cancer plasma proteome by isotope-coded affinity tagging method reveals biotinidase as a breast cancer biomarker. BMC Cancer. 2010;10:114. 